revista ANTHROPOLÓGICAS

Ano 24, 31(1): 220-248, 2020

\title{
As Violências das Práticas Empresariais: mineração, deslocamentos compulsórios e resistências no vale do Zambeze, Moçambique.
}

Albino Jose Eusébio ${ }^{a}$

\begin{abstract}
A instalação do megaprojeto de exploração de carvão mineral pela multinacional brasileira Vale, na Bacia Carbonifera de Moatize, região do vale do Zambeze, região central de Moçambique, transformou o distrito de Moatize num campo de deslocamentos compulsórios, violências e conflitos sociais. No presente artigo, analisase as diversas formas de resistência desenvolvidas pelas populações compulsoriamente deslocadas, seus repertórios, demandas e implicações sociais. Advoga-se que as ações coletivas de reivindicação social protagonizadas por essas populações, que são na sua maioria populações rurais (camponeses, oleiros), não só denunciam as práticas violentas, autoritárias e coloniais das empresas mineradoras e apresentam narrativas outras para uma reflexão crítica sobre a atual lógica de desenvolvimento em Moçambique, baseada na intensificação da exploração e exportação de commodities, como também tem a potencialidade de interferir positivamente na forma como vem se dando a expansão desenvolvimentista na região.

Mineração, Megaprojetos, Deslocamentos compulsórios, Ações coletivas, Resistências, Moatize.
\end{abstract}

O início do novo milênio foi marcado pelo aumento de grandes projetos de desenvolvimento, impulsionados por uma política governamental centrada na captação de grandes investimentos diretos estrangeiros para exploração e exportação de commodities. Moçambique

a Doutor em Sociologia e Antropologia pela UFPA. Pesquisador de Pós-Doutorado no IPPUR/UFRJ. Email: albinoeusebio@outlook.com; albino.acipol@gmail.com. 
se tornou atrativo para as grandes empresas multinacionais ligadas à área de hidrocarbonetos, de exploração energética, do agronegócio e de exploração mineral e tal atração tem contribuído para o aumento de Investimentos Diretos Estrangeiros (IDE) na área extrativa. De 2009 a 2014, por exemplo, do total de investimentos atraídos pelo Estado moçambicano, aproximadamente $70 \%$ foi destinado ao setor extrativo (Mimbire 2016).

$\mathrm{Na}$ área de exploração mineral, um número significativo de investimentos está concentrado na área do Vale do Zambeze, região central de Moçambique. Um dos maiores investimentos é o Projeto Moatize de exploração de carvão mineral, operado pela multinacional brasileira Vale. No decorrer da nossa análise, vamos explorar os contornos da chegada dos investimentos da Vale nessa região. Uma das consequências imediatas da instalação desse megaprojeto, nome dado em Moçambique a esses investimentos, foi o deslocamento compulsório de milhares de famílias que viviam na área concessionada. A maioria delas, classificadas como rurais, foram transferidas para a Comunidade de Cateme, na localidade de Kambulatsitsi, distrito de Moatize, a aproximadamente $30 \mathrm{~km}$ do seu local de origem. Dados colhidos durante a pesquisa doutoral realizada no primeiro semestre de 2016 e segundo semestre de 2017 indicam que o processo de deslocamento compulsório provocou transformações significativas em seus modos originais de viver, habitar, produzir e reproduzir-se. Essas transformações sociais se evidenciaram nos constantes lamentos sobre a realidade atual de vida em comparação com 'o antigamente', bem como em constantes ações de reivindicação contra o antagonismo existente entre o prometido e o realizado, e de modo geral, contra a violência das práticas empresariais e violação dos seus direitos. $\mathrm{O}$ deslocamento transformou Moatize num campo de resistência e no despertar e afirmação local da cidadania.

O propósito desse trabalho é analisar as diversas formas de resistência desenvolvidas pelas populações compulsoriamente deslocadas em Moatize, seus repertórios, demandas e implicações sociais. A nossa 
análise encontra-se dividida em dois pontos essenciais: no primeiro, exploramos os contornos da chegada dos investimentos da Vale na região. A chegada dessa multinacional não só marca uma nova fase na exploração carbonífera de Moatize, suspensa desde a década 80, como também uma nova lógica de exploração caracterizada pela 'mina a céu aberto' com efeitos ambientais e sociais significativos, sendo um deles a expropriação do território.

No segundo ponto, discorremos sobre as ações locais de reivindicação e mobilização social, tendo como lócus central de análise a comunidade de Cateme. A realidade de vida atual a que estão sujeitas as populações compulsoriamente deslocadas desperta ações de resistência que não se resumem somente a ações de confronto - tão significativas são as ações de ressignificação da vida e a busca cotidiana de novos campos de sobrevivência ou reprodução social e econômica. Seja como motoqueiro ou com uma feirinha de venda de tomate nas ruas mais movimentadas da comunidade, eles se engajam em novos campos de possibilidade de sobrevivência cotidiana, se negam a ser cúmplices do aniquilamento da sua própria existência, denunciam a violência da expropriação e se afirmam como sujeitos da sua própria história e trajetória de vida. A ressignificação da vida e a busca constante de novos campos de possibilidade de sobrevivência cotidiana é uma forma de (r)existência.

\section{Desenvolvimentismo e mineração no Vale do Zambeze: as minas de Moatize em perspectiva}

A região do vale do Zambeze ocupa, desde o tempo colonial, um lugar estratégico nas políticas de desenvolvimento e progresso nacional. O inventário realizado no governo Salazar (1930-1970) pelo Gabinete do Plano de Desenvolvimento da Região de Zambeze, entidade colonial que tinha como objetivo dar mais celeridade ao 'desenvolvimento econômico e social', permitiu mensurar o potencial mineralógico da região, incluindo as enormes reservas de carvão mineral de Moatize, consideradas atualmente umas das maiores do mundo ${ }^{1}$. 
O aumento dos preços de commodities no mercado mundial nos primórdios dos anos 2000 , estimulado pelo aumento da sua procura no mercado asiático, especialmente na China e Índia, tornaram a região do Vale Zambeze atrativa para as grandes multinacionais do setor da mineração. Atendendo a essas demandas, em 2002 foi aprovada uma nova lei de minas, garantindo, entre vários pontos, a prevalência das atividades mineiras sobre todas as formas de uso e apropriação do território (Moçambique 2002). Essa lei criou um contexto jurídico específico que permitiu, na prática, a possibilidade de um crescimento rápido do setor de mineração no país, dando espaço para a materialização de uma lógica desenvolvimentista baseada na exploração e exportação de commodities.

Em 2004, o governo moçambicano lançou um concurso internacional para concessionar as minas de carvão de Moatize, no qual concorreram várias empresas, entre elas a multinacional australiana BHP Billiton e a multinacional brasileira Vale. O concurso foi vencido pela multinacional brasileira Vale, constituindo o primeiro grande IDE brasileiro em Moçambique. Estudos minerais feitos pela empresa mostraram que a reserva tinha 1,87 milhões de toneladas de carvão bruto e vida útil de 35 anos, de modo que a mina seria a segunda maior do mundo a céu aberto (Rossi 2015). Em 26 de junho de 2007, a mineradora assinou através da sua subsidiária Rio Doce Moçambique Limitada (RDML) - entidade de direito moçambicano criada para desenvolver o projeto Moatize e deter a licença de propensão, pesquisa e concessão mineira - um contrato, estabelecendo um prazo de 25 anos renováveis por mais 25 anos, para exploração do carvão de Moatize em mina de céu aberto, numa área estimada em 23.780 hectares. Este espaço incluía áreas de ocupação imemorial ou datada pelas populações locais, na sua maioria camponesas na sua forma de organização, produção e reprodução social e econômica.

O projeto teve um investimento inicial - referente à instalação e exploração da primeira mina a céu aberto - de aproximadamente dois 
bilhões de dólares, sendo o maior projeto de investimento no setor mineiro no país. Contudo, a estimativa era de um investimento final de aproximadamente 8,5 bilhões de dólares, desde a extração até o escoamento do carvão mineral. O valor estimado da aquisição torna esse megaprojeto um dos maiores investimentos correntes do Brasil no continente africano e o primeiro grande investimento da Vale neste mesmo continente. Em 2010, a Vale expandiu o seu horizonte de investimentos para a Zâmbia, visando à exploração da mina de cobre de Lubambe a partir de uma joint venture com a African Rainbow Minerals, num investimento estimado em 400 milhões de dólares (Rossi 2015).

Em Moatize a produção de minério teve início em 2011 e, em 2013, atingiu uma produção de 4 milhões de toneladas, o que corresponde a $40 \%$ da capacidade instalada de produção (que é equivalente a 11 milhões de toneladas ao ano). Em 2014, a produção subiu para 5 milhões de toneladas, e para 5,5 milhões de toneladas em 2016, sendo 3,5 milhões de toneladas de carvão metalúrgico e 2 milhões de toneladas de carvão térmico (Vale, 2017). A produção total de carvão de Moatize em 2016 equivaleu a aproximadamente $80 \%$ da produção total do carvão da empresa, que foi de 7, 2 milhões de toneladas.

A Vale é também o maior investidor do Corredor Logístico de Nacala (CLN), junto com o Caminhos de Ferro de Moçambique (CFM), que oficialmente entrou em funcionamento em maio de 2017 (Nogueira 2017). Neste projeto a multinacional investiu na construção de $912 \mathrm{~km}$ de ferrovia que liga o distrito de Moatize ao distrito de Nacala-a-Velha, na província de Nampula, região norte de Moçambique, passando pela República do Malawi. Investiu ainda na construção do porto de escoamento de carvão na mesma região. Entre os vários efeitos sociais e ambientais do projeto, estima-se que mais de duas mil famílias foram compulsoriamente deslocadas ao longo do corredor de Nacala. O primeiro trecho do trajeto, de $230 \mathrm{~km}$, partindo da área da mina de Moatize à Cuamba, passando pela república de Malawi, 
foi construído do zero. No segundo trecho, de $682 \mathrm{~km}$, que segue de Cuamba até a cidade portuária de Nacala, já existia uma linha férrea em operação que foi reformada.

A construção dessa linha férrea e do porto de escoamento em $\mathrm{Na}$ cala tinha como objetivo diminuir a dependência do escoamento de carvão pela Linha de Sena e Porto da Beira, região central de Moçambique. A ideia era criar um sistema integrado de produção - mina, ferrovia e porto - nos moldes do Projeto de Ferro Carajás, situado no município de Parauapebas, estado do Pará, região norte do Brasil (Palheta da Silva 2013; Sant'Ana Júnior \& Cardoso 2016; Sant 'Ana Júnior \& Alves 2018). A ferrovia 'Moatize-Nacala' passa pelo distrito de Monapo, também na província de Nampula, onde a Vale está em processo de prospecção e pesquisa para a exploração das recém-encontradas reservas de fosfato que "colocam o país na posição de terceiro maior produtor mundial, abrindo perspectivas para o mercado de fertilizantes" (Silva 2014:27).

As atividades de exploração em Moatize são feitas em mina de carvão a céu aberto. A sua instalação obrigou inicialmente o deslocamento compulsório de 1365 famílias, em tempo recorde, entre os dias 9 de novembro de 2009 e 21 de abril de 2010, dos bairros Chipanga, Mithethe, Bagamoyo e Malabwé. Entre estas, aproximadamente 300 famílias foram deslocadas mediante indenização em dinheiro para reconstruírem, pelos seus próprios caminhos, suas vidas em outros locais; e 289 foram deslocadas para o Bairro 25 de Setembro, também conhecido como 'Bairro 5', nos arredores da Vila Sede de Moatize. Esse bairro foi destinado para aqueles que eram funcionários, trabalhadores e comerciantes. Aproximadamente 714 famílias, que foram classificadas como rurais, foram compulsoriamente deslocadas para Cateme, a $36 \mathrm{~km}$ da Vila de Moatize (Governo do Distrito de Moatize 2015). Tal como podemos constatar nas narrativas a seguir, o deslocamento compulsório transformou de forma significativa os seus modos de viver, habitar e produzir, afetando diretamente as bases de sua reprodução socioeconômica. 
"Vieram nos deitar aqui como se fossemos lixo, enquanto somos humanos...”” o que as próprias populações dizem sobre os 'novos lugares'

Dona R.E.T. Bagamoyo mudou-se para o bairro Bagamoyo, arredores da vila municipal de Moatize, no final da década 90, após seu casamento, vinda do distrito de Mutarara. É manyungwe, nome em que são identificadas as pessoas do grupo étnico Nyungwe. $\mathrm{O}$ marido foi o primeiro a migrar, num processo típico de migração camponesa semelhante ao analisado por Klaas Woortmann (2009) no seu estudo etnográfico sobre os sitiantes do Sergipe nordeste do Brasil, bem como por Sara Mercandalli (Mercandalli 2015; Mercandalli \& Anseeuw 2014) em sua pesquisa sobre o sul de Moçambique.

$\mathrm{Na}$ sua pesquisa sobre as populações camponesas da localidade Leonzoane, no distrito de Massinga, a poucos quilômetros de Maxixe, cidade onde nasci e cresci, na província de Inhambane, região sul de Moçambique, Sara Mercandalli constata que a reprodução social das sociedades camponesas desta região é extremamente dependente de atividades extra-agrícolas, com maior destaque para o processo de migração para o trabalho em minas da África do Sul (Mercandalli 2015; Mercandalli \& Anseeuw 2014). De fato, é comum nas zonas rurais do sul de Moçambique expressões como $i$ mu johnny johnny (é mineiro) ou a nuna wa yena i mu johnny johnny (o marido dela é um mineiro) - apesar de johnny ser uma expressão que remete a Johanesburgo, principal e maior cidade da África do Sul, não implica necessariamente uma localização territorial, mas uma 'categoria classificatória' (Woortmann 2009) que nesse contexto identifica e distingue o trabalhador das minas da África do Sul de outras categorias sociais.

Diferente do johnny como é típico no sul de Moçambique desde o tempo colonial, G.M. Bagamoyo, marido da dona R.E.T. Bagamoyo, migrou para a vila de Moatize em busca de novas possibilidades de sobrevivência.

$\mathrm{O}$ meu marido saiu primeiro para Moatize à procura de fazer a vida e depois voltou para me casar. Após o casamento, voltamos juntos para morar cá [bairro Bagamoyo, na vila de Moatize], depois é que 
apareceu a Vale com todas as suas promessas e nos tirou para aqui [Cateme]. Eu e meu marido nunca fomos funcionários públicos, sempre vivemos da machamba [nome dado em Moçambique à uma porção de terra dedicada à produção agrícola] e de negócios particulares. Além da agricultura, eu também fazia negócios, sempre fiz negócios de venda de lenha e comprava tomate e outros produtos agrícolas no distrito de Angônia para vender em Moatize. O meu marido é oleiro, produzia tijolos queimados. Mas aqui o negócio de tijolo não sai por causa da falta de matéria-prima e da distância para o mercado. Não há poder de compra para o negócio andar. Com o dinheiro de indenização da segunda machamba, construí esses quartos para alugar, mas não consigo clientes, estão todos vazios. Mandei fazer isso para ver se conseguia alguma renda, mas não está dando certo, não consigo clientes para alugar. Continuo fazendo alguns negócios, compro milho, este que você está a ver aqui, em Angônia, e tento vender aqui no mercado. Costumo comprar também outros produtos agrícolas em função da época, batata doce, tomate também, para vender aqui no mercado. A machamba e esses produtos é que garantem atualmente a nossa sobrevivência. No início, eu e meu marido construímos uma banca ali no mercado onde vendíamos produtos como açúcar, arroz, óleo, mas encerramos por falta de clientes. Os produtos tinham pouca rotação por falta de clientes. Esses negócios são necessários porque a machamba que me deram não me permite um bom rendimento, diferente de lá, as machambas daqui não produzem bem. Se a Vale cumprisse com o que nos prometeu, não estaríamos a viver nessas condições. A Vale deve cumprir com o que nos prometeu. A Vale é que nos tirou de lá para aqui, a responsabilidade é dela. (Sra.

R.E.T. Bagamoyo 2016).

Foi também o casamento que fez com que a Dona I. Chipanga fosse morar no Bairro Chipanga em 1988. Manyungwe, mãe de oito filhos (dois já casados com família própria e seis morando com ela), nasceu em Magoe e cresceu em Chitima, sede do Distrito de Cahora Bassa. Migrou para Moatize e passou a morar no bairro Chipanga depois do casamento. "Meu marido era militar e foi nomeado para trabalhar na base militar de Moatize". Anos depois, C. Chipanga, seu marido, foi desmobilizado e passou a se dedicar a negócios particulares. 
Ele trabalha no mercado vendendo roupa, tem uma banca lá [em Moatize] onde vende roupa. Ele tem que ir lá porque é onde tem movimento de pessoas e poder de compra, aqui não tem nada disso. Todos os dias de manhã viaja para a cidade para fazer negócio e volta de tarde. Meu marido sempre trabalhou com esse negócio, a diferença é que agora ele tem que pegar chapa diariamente para lá e isso tem muitos custos. Eu particularmente trabalhei sempre na machamba e produzia pombe $e^{2}$. Continuo produzindo pombe, mas os ganhos não são os mesmos porque aqui não tem movimento [poucos consumidores]. Por isso aqui a vida é difícil.

A falta de alternativas à agricultura é, na visão do Sr. F.P.D. Mithethe (2016), morador, nascido e crescido no bairro Mithethe, uma das coisas que torna a realidade atual de vida 'cá' difícil em comparação com a vida 'lá'. A situação fica grave em momentos de falta de chuva (que são comuns em Cateme), elemento natural imprescindível para o tipo de agricultura praticado na comunidade.

Para mim aqui é um bom lugar, porém tem pequenos problemas. Esse ano, como não choveu, estamos um pouco mal porque dependemos de colimar [cultivar a terra], lá era nossa zona, tinha diversas alternativas. A lenha e a produção de carvão complementavam a produção da machamba. Era próximo da vila então eu produzia também carvão e punha na bicicleta para vender na vila, coisa que aqui é difícil fazer. Mesmo tendo lenha, fazer carvão para levar para a vila é muito longe. Aqui a distância dificulta muita coisa. Lá em Mithethe para a vila não era longe, amarrávamos os sacos na bicicleta e íamos vender. Eles prometeram projetos, mas as pessoas estão aqui vadiando. Até que houve espaço para trabalhar quando ainda estavam a construir aqui, mas depois tudo mudou, agora só estamos vadiando. Os jovens só ficam em casa. Para mim, nos deixar aqui não é problema, o problema são as condições de sobrevivência. Lá nós fazíamos as coisas da nossa maneira, era nossa zona, conhecíamos tudo. Aqui não tem problema enquanto espaço, mas trabalho e serviço não têm aqui. Deixamos lá nossos projetos e nossa vida para vir ficar aqui sem fazer quase nada, por isso estamos a sofrer aqui. Eu era oleiro e produzia carvão vegetal. Eles prometeram que aqui iam criar condições para continuar com a atividade, mas desde 2009 até agora nada se fez. Agora trabalho mais na machamba. Colimar estamos a colimar, mas carvão, tijolos, lenha, não tem como fazer para vender. Lá para ter machamba era só pedir 
a outra pessoa, mas aqui é só comprar. É outra zona e tem outros modos de fazer as coisas. Assim é só desenrascar para viver numa situação que não fomos nós que criamos. Nós não viemos aqui por vontade própria, foram eles que nos obrigaram. Nós recusávamos, nas reuniões, vir para aqui. Mas eles prometeram, prometeram e quando chegamos aqui, nada. Lá a gente vivia praticamente nos dois sítios, Chipanga e Mithethe, tínhamos casa em Chipanga e Mithethe. Os dois bairros eram muito pertos, Chipanga tinha fontanária e rio que não acabava água. Não tinha o problema de água que temos aqui.

A água é um dos graves problemas enfrentados em Cateme. A empresa optou por colocar fontes públicas nos quatro bairros, além de um sistema de canalização e distribuição direta nas casas. Esse seria, segundo alguns interlocutores, um sistema mais viável, porém as avarias constantes tornam o acesso a água muito limitado.

Atualmente faz-se tanta bicha [fila] para ter acesso a água, ou temos que cavar poços próximo do rio para ter acesso a água e poder fazer algumas atividades. Neste momento, em cada bairro só tem uma torneira que está operacional, as outras estão avariadas. A pessoa tem que ir lá cedo tirar e ficar todo dia com essa pouca água, para no fim do dia ir fazer outra grande bicha. Às vezes faz-se bicha no meio dia para só chegar a sua vez de catar água no fim de tarde. (Sr. R.P.B. Chipanga 2016).

O frágil sistema de abastecimento de água vem afetando o processo de criação de animais.

Alguns cabritos morreram por falta de água. Aqui quando viemos não tinha cabrito, nos é que trouxemos, o que faltou são as condições para criar. (Sr. J. P. Chipanga 2016).

Foi a falta de água associada à prevalência de terra imprópria que fizeram com que o Sr. R.P.B. Chipanga (2016) não insistisse na sua antiga atividade de oleiro.

Aqui não tem terra própria para fazer tijolos, o terreno não permite, a areia daqui não é própria. Tem também a falta de água, e tijolos requerem muita água. $\mathrm{O}$ acesso é muito limitado. 
Para o Sr. P.A.S. Mithethe (2016), não há dúvidas que sair de 'lá' para 'aqui' foi "um retrocesso em muitas coisas, embora lá tivéssemos casas de pau a pique e aqui tenhamos de alvenaria apesar dos problemas que tem, mas quando vamos para outras coisas, a vida aqui ficou pior". Continua ele,

por exemplo, eu trazia animais de lá de Mithethe, eu tinha quase 40 cabeças de cabritos, mas quando cheguei aqui, perdi tudo. Muitos deles morreram, outros foram roubados. Voltei ao zero. Assim, não tenho nenhum animal, só tenho esses cães aqui [risos]. Aqui se rouba muito, não roubam só uma ou duas cabeças, roubam todo o curral, ameaçam matar o pastor. Não sabemos donde vêm os ladrões, mas acredito que muitos vêm da Vila e entram em coordenação com alguns daqui, por isso, vão especificamente para os maiores produtores. Este ano estamos mal, tentamos colimar, mas como faltou chuva, quase toda minha produção secou. Essa imagem que estás a ver aqui na horta é a mesma coisa lá na machamba: tudo secou. A grande diferença entre aqui em Cateme e lá [Mithethe] é que em situações como essas que a produção na machamba não dava o esperado, tínhamos outras alternativas, cortar lenha, fazer carvão para vender na vila. Eu tinha esses animais que ia vender na vila. Mas aqui isso é impossivel fazer, primeiro, porque tal lenha não tem, nem material para produção de carvão. Segundo, para quem tenta, o custo de transporte dificulta muito as coisas. Como carregar carvão para vila, $38 \mathrm{~km}$ é muito difícil. Aqui ninguém compra. No ano passado houve fome, mas provocada pela chuva. Choveu muito e inundou quase tudo, este ano é a seca e com essa seca a nossa situação ficou pior. A agricultura é a nossa base. Lá de onde nós saímos tínhamos nossas machambas que capinávamos mapira e milho, mas quando viemos aqui deram só uma machamba por cada família, a outra deram em dinheiro. Foram 119 mil. Mas para dar esse dinheiro foi uma grande confusão. Cada machamba que deram tem um hectare, isso para dizer que cada família tem um hectare. Para aumentar o espaço de produção, eu dividi esse meu quintal para fazer horta aqui. Esse meu quintal mede $80 / 45$. Na verdade todas as casas têm quintal dessa dimensão. Então aproveito esse espaço para produzir alguma coisa também.

A existência 'lá' de diversas alternativas, viabilizadas pela existência de 'muitos recursos', pelo menos em comparação com Cateme, permitiam à Sra. F. C. Mithethe (2016) superar situações de crises 
que, segundo ela, são situações em que a produção na machamba era por diversas razões afetada e não alcançava os resultados esperados.

Aqui vivo uma situação de sofrimento e como já perdi meu marido a situação fica pior. Lá pelo menos tinham muitos recursos que nos ajudavam a superar situações de crise. Se a empresa pelo menos um dia falar para a gente voltar às nossas terras, eu sou uma das pessoas que voltaria sem nenhum receio, porque lá estava a viver melhor.

A localização privilegiada nas margens do rio Revúboe tornava a produção agrícola em Malábue muito mais eficiente em comparação com as machambas distribuídas em Cateme. Tal como destaca Sr. R.C.C. Malábue (2016), uma das lideranças do bairro Malabue,

para a parte de agricultura não tínhamos problemas, estávamos à beira do rio. Por estar à beira do rio, todas as épocas conseguíamos produzir verduras sem problemas. Fazíamos a pesca. Para além da pesca, fazíamos esteiras e vendíamos em Moatize. Era uma distância de pelo menos $10 \mathrm{~km}$ para a vila de Moatize. Eu sempre vivi de agricultura, tinha machamba onde produzia as verduras, mas também praticava a pesca. Mas aqui está difícil porque não existe a cultura de segunda época, só primeira época, enquanto lá, era todo ano. Mas aqui não. A minha população não sabia o que aqui vieram apreender e são obrigados a aprender como secar as culturas para poder aguentar até outra época. Lá não acontecia, era tudo fresco. Peixe era fresco, comprado ou pescado direto pela pessoa no rio.

Embora a empresa tenha prometido levar em conta essa localização privilegiada no rio Revúboe, como critério na distribuição das machambas, na prática ela não se efetivou. A maioria das pessoas do bairro Malábue recebeu machambas em áreas com um solo impróprio para produção agrícola, 'áreas cheias de pedras', como no caso da Sra. F.C. Malábue. Algumas poucas pessoas, como é o caso do Sr. P.C. Malábue que recebeu machambas em melhores condições em comparação com a maioria dos 'reassentados', convivem cotidianamente com o dilema de ser arrancado ou não pelos nativos.

Minha machamba era $75 \%$ bom e 25\% mau, tem muitos que receberam em áreas $100 \%$ pedra. Tem um [nativo] que vinha aqui dizer 
que quer sua machamba porque não foi indenizado pela Vale. Eu disse para ele que já passava muito tempo desde que recebi aquela machamba, em 2010. Mandei-o ir ter com a Vale. E esses dias não têm vindo.

De fato, Cateme não era uma zona desabitada. Dados históricos indicam que foi um aldeamento colonial. Não foi transformado em aldeia comunal, tal como aconteceu com alguns aldeamentos coloniais de Moatize, no âmbito da política socialista de modernização rural centradas nas aldeias comunais e cooperativização agrícola. Nesse processo, logicamente que uma parte da população pode ter se dispersado de volta às suas terras ancestrais, ou em busca de viver a vida do seu modo em outros locais escolhidos ao seu próprio critério, porém, a área continuou sendo uma área habitada.

Há pessoas que já viviam aqui antes de nós chegarmos. Lá em frente, na entrada da comunidade, dá para ver essas pessoas. O que acompanhei é que a Vale prometeu que ia lhes dar os mesmos direitos dos reassentados. $\mathrm{O}$ acordo previa que eles deviam dividir as machambas conosco. Das 45 famílias, a Vale só contemplou 21, e daí começou a confusão. As pessoas que receberam foram espalhadas nos quatro bairros de forma aleatória, então aqueles que não foram contemplados se sentiram traídos e arrancaram as machambas de volta. O problema até agora não está resolvido, já fizemos carta para o governo e o processo ainda está em andamento. A chefe da localidade, do posto administrativo e a administradora já deram visto no documento. (Sr. P.A.S. Mithethe 2016).

Para o Sr. J.P. Chipanga (2016), não se pode responsabilizar os nativos por levarem as machambas de volta, mas a empresa que descumpriu os acordos feitos.

Tudo que a empresa prometeu a eles, não cumpriu também, tal como fez conosco. Tinham dito que iam lhes dar casas, mas depois não deram, então eles levaram as machambas deles de volta. Foi nesse contexto que eles arrancaram as machambas que tinham aceitado ceder para os reassentados. 
A omissão do governo é, para o Sr. M.A.Z. Bagamoyo (2016), uma das lideranças de Cateme, a causa dos diversos problemas que afetam a vida cotidiana em Cateme.

Você chegava na minha casa e dizia: 'sim, senhor, é casa do senhor M.A.Z', mas olha para isto. Viver nessa situação me deixa indignado. $\mathrm{O}$ governo deveria ser a primeira pessoa as nos defender, o que não acontece. Esses da empresa são de fora que estão a vir explorar aqui. Nós somos daqui mesmo. Além de nos deixarem limpos e desenvolvidos, esses estão a nos deixar pobres. Muitas coisas que eu tinha acumulado estão a acabar por vender. Quando a gente reivindica, eles só sabem trazer armas. Olha bem essas casas, vais ver que casas de banho e latrinas estão sem chapas [de cobertura], as pessoas estão a tirar para vender, para comprar comida e outras coisas. Vieram nos deitar aqui como se fossemos lixo enquanto somos humanos, tínhamos nossos bens e nossas próprias condições de vida lá nas nossas casas de onde nos tiraram. Estão a nos tratar como se fossemos refugiados. Nós não somos refugiados, somos donos dessa província. Um estrangeiro vem explorar aqui e enriquecer lá no país dele e nós ficamos pobres assim como estamos. Faz-se isso? Muitos de nós aqui não temos emprego, por isso está cheio de gente que não faz nada e de ladrões. A primeira reivindicação que fizemos foi sobre as machambas que se localizam, na sua maioria, em locais com pedras e sem condições adequadas para a produção. Como reivindicamos e não nos davam a mínima, decidimos bloquear a linha férrea. Não destruímos, só bloqueamos para não passar comboio. Era uma forma de lhes chamar para nos ouvirem. Enviaram seis polícias e viram que era muita gente. Ligaram para a província dizendo que era muita gente. $\mathrm{O}$ governo provincial enviou uma unidade de intervenção rápida. Chegamos àquela ação porque não nos ouviam, nos ignoravam quando dizíamos que aqui as coisas não estão bem. Ninguém veio para aqui por vontade própria, foi a empresa em coordenação com o governo que nos trouxe aqui. Mas eles mandam militares para nos violentar. $\mathrm{O}$ que custa eles virem fazer uma reunião com a população e ouvir as nossas reivindicações? A gente manda cartas para o governo sobre nossas preocupações, não respondem nada. Alguns que vão lá reivindicar são detidos logo para intimidar os outros a não se atreverem a fazer isso. Por que o governo não pressiona? Por que continua ignorando as promessas feitas pela empresa? Cada vez mais aqui estamos a ficar pobres do que lá onde estávamos a viver. A minha casa lá era melhor que essa casa aqui. Essa minha é morfologia C. Lá eu 
era oleiro, fabricava tijolos e vendia. Muitos de Bagamoyo tinham seus projetos de olaria. Aqui mesmo se eu continuar com esse projeto, quem vai comprar? Nem carvão, nem tijolos, nem lenha. Eu continuo fazendo, mas desde 2015 até hoje está aí todo tijolo ninguém está a comprar. As pessoas não vão sair da vila para comprar aqui se podem comprar lá mesmo. Os custos para levar daqui para lá são altos. Na machamba, a produção está sempre abaixo do esperado, este ano a situação agravou-se pela seca. Com os 119 mil meticais que nos deram de indenização da segunda machamba, mandei instalar energia elétrica e comprei alguns eletrodomésticos e mobiliário para casa. Mas com essa seca, algumas coisas estou a vender de novo para comprar comida e alguns materiais paras as crianças irem à escola. As pessoas vendem congelador a dois mil que compraram a cinco ou seis [meticais]. Estou a empobrecer. (Sr. M.A.Z. Bagamoyo 2016).

\section{"Naquela manifestação levamos muita porrada [...], mas conseguimos alcançar alguns objetivos": as ações coletivas de mobilização e reivindicação social}

A mobilização social ${ }^{3}$ é a arma dos dominados para tentar impor suas visões sobre o mundo. "Os dominantes existem sempre, ao passo que os dominados só existem quando se mobilizam ou se munem de instrumentos de representação” (Bourdieu 2004:189). O deslocamento compulsório imposto pela multinacional brasileira Vale transformou Moatize não só num campo de violação de direitos como também no campo de resistência. A violência do deslocamento está caricaturada na realidade de vida cotidiana nos 'novos lugares', as narrativas acima testemunham essa violência. Diversas pesquisas têm também mostrado as dificuldades vividas pelas populações compulsoriamente deslocadas em Moatize (Human Rights Watch 2013; Sitoe \& Queface 2015; Amaral 2016; Osorio \& Cruz e Silva 2017).

Num processo de afirmação local da cidadania, as populações compulsoriamente deslocadas se engajam em ações coletivas em defesa dos seus direitos e denunciam as práticas e ações desastrosas das empresas capitalistas. No caso da comunidade de Cateme - área onde foram reassentadas as famílias classificadas de rurais - a carta enviada 
para o governo distrital e para ONGs denunciando a violação dos seus direitos; a solicitação de encontro com órgãos governamentais para expor os problemas da comunidade; o acampamento nas instalações do governo distrital, o bloqueio da ferrovia de transporte de carvão mineral que passa, por exemplo, a poucos metros da comunidade de Cateme, a invasão coletiva da área de operações de extração e a consequente paralização da produção são algumas das ações coletivas de reivindicação desenvolvidas. Em 2012, por exemplo, aproximadamente dois anos após o deslocamento, a comunidade de Cateme, reivindicando o cumprimento das diversas promessas feitas (acesso à água, terra fértil, energia, indenização, transporte coletivo, saúde, educação etc.), bloqueou a linha férrea de transporte de carvão que passa a poucos metros da comunidade de Cateme. Pela solicitação da empresa, essa ação coletiva foi violentamente reprimida pela então Força de Intervenção Rápida (FIR), unidade de elite da Polícia da República de Moçambique (PRM), o que reforça a prevalência práticas empresariais violentas de controle e gestão de resistências se apropriando dos aparelhos estatais de repressão.

Naquela manifestação levamos muita porrada com a FIR, mas conseguimos alcançar alguns objetivos. Colocaram energia nas casas, coisa que só tinha lá na avenida principal, aumentaram os furos de água nos bairros, asfaltaram a estrada de acesso aqui na comunidade. Mas a questão de emprego ainda não encontramos nada. (Sr. P.A.S. Mithethe 2016).

Para o Sr. D.B.X. Chipanga (2016), a ação da polícia é injustificável e incompreensível pois,

nunca fizemos manifestação sem dar comunicação à empresa, ao governo distrital, aos postos policiais. Só que nosso governo sempre é assim, nunca vai aceitar. Mesmo que levemos tudo dentro das normas [legais], eles sempre procuram uma forma de intimidar as pessoas, o problema do nosso governo é esse. As nossas manifestações não são contra o governo, mas sim contra [as ações da] empresa, mas eles chegam com armas e começam a bater pessoas. 
Apesar da violência, a mobilização de 2012 teve posteriormente, alguns resultados incipientemente visíveis como, por exemplo, a eletrificação das vias públicas e das residências, a reabilitação das casas, a ampliação do sistema de abastecimento de água, entre outros. $\mathrm{O}$ medo de represálias tem marcado a vida cotidiana em Cateme. Foi comum durante o trabalho de campo ouvir palavras como: "não é para me denunciar..."; "vou te contar, mas não fala que eu é que disse..."; "têm pessoas que são levadas a noite para vila, por isso não fala meu nome...".

A grande cobertura que vem sendo dada às ações coletivas de resistência em Moatize pelos órgãos de comunicação nacionais e internacionais e as constantes denúncias das organizações da sociedade civil moçambicana (Associação de Apoio e Assistência Jurídica a Comunidades - AAAJC ${ }^{4}$, Acção Acadêmica para o Desenvolvimento das Comunidades Rurais - ADECRU) e ONGs internacionais (Articulação Internacional dos Atingidos pela Vale, OXFAM. Esta tem regularmente desenvolvido seminários sobre os processos de consulta comunitária e os direitos legais das comunidades locais) visibilizaram e ainda visibilizam internacionalmente as práticas de expropriação e violência da mineradora e as ações de resistência em Moatize, tornando as práticas da empresa um problema público, gerando um repúdio internacional à mineradora e aumentando, de certa forma, a pressão sobre as suas práticas predatórias. As páginas online dessas organizações nacionais e internacionais tem sido um importante espaço de denúncia das práticas violentas das empresas de mineração e de visibilização das ações coletivas locais de resistências ${ }^{5}$.

$\mathrm{O}$ antagonismo entre o prometido e o cumprido continua no centro das ações coletivas de reivindicação e mobilização social. As demandas ainda centram-se na questão da canalização da água para as residências; promessas de emprego; problemas de infiltração e rachaduras nas casas, que mesmo após a primeira intervenção da empresa continuam visíveis; machambas para aproximadamente 40 famílias compulsoriamente deslocadas que, após terem recebido o primeiro 
hectare de terra para agricultura, foram arrancadas pelos nativos devido a uma negociação mal concluída com a empresa mineradora e o governo distrital; a situação dos oleiros que ainda reclamam a indenização prometida devido à destruição dos seus fornos e o fechamento da área de produção no âmbito da instalação do projeto; o destino dos $2.75 \%$ das receitas geradas pela exploração mineira e petroleira que por lei são canalizadas para o desenvolvimento das comunidades nas áreas onde se localizam os projetos. Na visão de alguns interlocutores, esse valor deveria ser usado para melhoria das condições de infraestrutura no 'novo lugar', fato que não tem se verificado. "Não queremos o dinheiro só para nós, mas pode-se usar primeiro esse dinheiro para resolver os nossos problemas aqui e depois pode-se usar para outros planos do governo distrital..." (SR. D.B.X. Chipanga 2016).

A constante fuga de responsabilidade por parte do governo distrital e da mineradora Vale - a empresa remete a solução das demandas das comunidades atingidas ao governo distrital, e o governo, por sua vez, remete à mineradora - reforça o sentimento de abandono. Este, porém, é mais imputado ao governo distrital do que à Vale, primeiro porque, na visão de alguns interlocutores, assim como um 'pai', o governo deveria interceder por 'seus filhos'; segundo, porque "o governo na verdade é que teve a maior força para nos tirar de lá” (SRA. A.P.F. Mithethe 2016).

Para o Sr. F.P.D. Mithethe (2016), o governo tem uma grande responsabilidade na atual e difícil situação da vida em Cateme porque deveria ser ele a exigir da empresa o cumprimento das suas obrigações.

[...] Mas nada disso fazem. Eles defendem a empresa contra nós. Eles podiam exigir à empresa cumprir com as promessas feitas, mas nada fazem. O governo é culpado por estarem a nos maltratar. Por que estão a defender a empresa contra nós? Porque estão a comer as nossas custas. Nós não queríamos vir para aqui. Se tivessem nos deixado lá, não podíamos chatear ninguém, nem governo, nem a empresa, porque nós vivíamos à nossa maneira. Mandaram-nos para aqui e não cumprem nada do que prometeram, eles estão lá na cidade, lá em Maputo [capital do país, onde se localiza a sede da empresa] e nós aqui a sofrermos. Podiam comer muito, mas nos 
dar um pouco também. Meu sentimento é de indignação. Deviam dar-nos alguma coisa do que prometeram. Só estavam as nos namorar só, por isso falaram muita coisa e diziam que iam fazer isso e aquilo, e quando chegamos aqui não vimos nada disso.

\section{“Agora sou motoqueiro, a vida não pode parar...": lutas, resistências e (novas) existências.}

O Sr. E.M.T é casado e pai de noves filhos, sendo três mulheres e seis homens. A maioria dos filhos mora com ele 'aqui' ${ }^{6} \mathrm{em}$ 'ChipangaCateme'. O mais velho, que é operador de máquinas numa das mineradoras que atua em Moatize, mora na vila-sede, também é casado e tem filhos. Os outros sete filhos continuam morando com ele na casa modelo A, composta por um quarto e sala. A cozinha externa e o banheiro são algumas das construções que completam a paisagem residencial.

O Sr. E.M.T. Chipanga, morava no bairro 'Chipanga - Moatize' desde o seu nascimento em 1962. "Eu nasci lá e cresci lá e só me mudei de lá para aqui em 2010”. Os seus pais são de 'lá', os seus avós também, foi lá onde casou e todos os seus filhos nasceram. Segundo ele, todos os seus ancestrais são de Chipanga. Os pais eram camponeses, "sempre vivemos da machamba", atividade que ele abraçou também, porém, tal como afirma, não dependia totalmente dela: "além da machamba eu também era oleiro e produzia carvão”. A família do Sr. E.M.T. Chipanga é uma das 714 famílias - isso segundo dados oficiais do Governo Distrital de Moatize (2015) - dos bairros Chipanga, Mithethe, Bagamoyo e Malábue que, perversamente classificadas como rurais, foram compulsoriamente deslocadas para Cateme.

Encontramos o Sr. E.M.T. Chipanga no posto policial de Cateme quando chegamos àquele local, durante a primeira fase da pesquisa de campo no primeiro trimestre de 2016. Ele se deslocara ao posto policial naquele dia para se informar sobre as motivações que levaram à soltura de duas pessoas que ele capturara, suspeitos de furtarem milho na sua machamba. Contou nos que naquele dia ficou sabendo que elas haviam sido soltas sem que lhe dessem ne- 
nhuma informação. Segundo ele, aquilo não ficaria assim, chegaria ao Administrador do Distrito e ao Governador Provincial, se fosse necessário, para ver restabelecida a justiça que passava pela recuperação do seu milho. Em conversas posteriores, fiquei sabendo que as pessoas responsáveis pelo furto não eram 'reassentadas', mas sim umas das várias que se deslocam para Cateme em busca do que Gilberto Velho denominou de novos campos de possibilidade (Velho 2013) de sobrevivência cotidiana.

O milho roubado não era da machamba dada pela mineradora no processo de reassentamento: "comprei com meu dinheiro". O Sr. E.M.T. Chipanga recusou-se a receber a machamba dada pela empresa por se localizar num local 'cheio de pedras' e sem mínimas condições para a produção agrícola e exigiu que a empresa procurasse uma machamba num lugar adequado. $\mathrm{O}$ processo se alastra desde a sua chegada a Cateme sem uma solução à vista, "nem a empresa nem o governo diz alguma coisa”. A falta de terra 'própria e de qualidade', de clientes e de água, que caracteriza a comunidade de Cateme e que agrega mais custos à produção, o impediu de dar continuidade à atividade de produção de tijolos. $\mathrm{O}$ mesmo aconteceu com a produção de carvão vegetal.

Pelas suas atividades de olaria recebeu, em 2012, tal como todos os oleiros das áreas deslocadas, o valor de sessenta mil meticais que a mineradora assume como indenização pelo encerramento dos seus fornos e os oleiros entendem como compensação pelo tempo em que ficaram sem produzir até aquele momento. O Sr. E.M.T. Chipanga também recusa que aquele fosse o valor acordado para indenização. Pergunta-se sobre os critérios usados para o seu cálculo e defende, tal como os outros oleiros, que uma nova forma de cálculo deva ser apresentada. Os sessenta mil meticais pagos não podem ser assumidos como indenização. Também recebeu o valor de cento e dezenove mil meticais como indenização do segundo hectare da machamba.

No acordo oralmente estabelecido entre a empresa e as populações antes do reassentamento, cada família receberia dois hectares de 
machamba para diversificar a produção. Enquanto em uma produz mapira (sorghum bicolor), em outra produz milho (zea mays), por exemplo. Essa era a prática nos seus locais de origem. Porém, a empresa concedeu um hectare para cada família optando por indenizar o outro hectare. É provável que a falta de espaço para o segundo hectare, reflexo de um frágil planejamento, possa ter contribuído para essa decisão de atribuição de um hectare e indenização do segundo.

Contudo, o importante a destacar aqui é que foi com esse dinheiro que o Sr. E.M.T. Chipanga, que recusara a machamba concedida pela empresa por se localizar no lugar 'cheio de pedras', comprou dos 'nativos' (antigos moradores da área) a machamba em que o milho fora furtado. Foi com uma parte desse dinheiro que também comprou uma moto, razão pela qual atualmente ele é também mototaxista. "Para viver, a pessoa deve desenrascar. Agora sou motoqueiro, a vida não pode parar. Vivo mesmo desse trabalho que estou a fazer, carregar pessoas daqui para ali", disse-nos ele, enquanto tomávamos um refrigerante no mercado de Cateme para refrescar a garganta depois de tantos movimentos que fizemos, primeiro de Cateme para Mualadzi (centro de reassentamento da mineradora Rio Tinto), depois dentro da própria comunidade, da casa de um líder para o outro.

A mulher e os filhos cuidam da machamba enquanto ele se dedica a essa atividade de 'carregar pessoas daqui para ali', e assim vai. $\mathrm{O}$ que pretendemos demostrar com essa pequena história de vida do Sr. E.M.T Chipanga é que os lamentos sobre as promessas não cumpridas e sobre a violação dos seus direitos fazem parte do seu cotidiano e acionam, em função disso, ações coletivas locais de resistência, num autêntico processo de afirmação local da cidadania. Mas a resistência não se resume exclusivamente a elas, em ações cotidianas de confronto. Ser motoqueiro, 'carregar pessoas daqui para ali', criar uma banquinha (feirinha) nos arredores do mercado ou nas vias de maior circulação na comunidade para vender tomate ou cebola, produzidos na sua própria machamba ou comprados (para revender) de outros locais, são também formas de (r)existência. 
Essas ações - singularizadas na história do Sr. EMT Chipanga, mas que na realidade são plurais e dependem da trajetória de cada família - se, por um lado, denunciam a violência do deslocamento, seus impactos nas formas de reprodução social e econômica, por outro demostram que as populações de Cateme se negam a ser cúmplices da destruição da sua própria existência. Ser motoqueiro e/ou criar uma feirinha é uma forma de (r)existência. Eles sabem, à medida que o tempo vai passando, que não podem esperar muito das promessas feitas pela empresa, muito menos do discurso de desenvolvimento, melhoria de vida ("deixem os brancos trabalharem para vossos filhos terem emprego" - essas eram as palavras que, segundo os interlocutores, eram ouvidas nos diversos encontros com autoridades administrativas locais, distritais, provinciais e nacionais) do governo e da empresa. Cada dia que passa, fica cada vez mais claro que o desenvolvimento só lhes contempla enquanto 'sujeitos de sacrifício' (Acselrad 2004a). Só eles mesmos podem ser sujeitos das suas próprias trajetórias e histórias de vidas. Ser motoqueiro e/ou criar uma feirinha é uma forma de resistência e existência.

\section{Considerações finais}

A sociologia, ao abordar a realidade de vida cotidiana dos diversos grupos sociais colocados, por exemplo, à margem das políticas de desenvolvimento nacional, mais do que denunciar os diversos problemas que os atinge, deve criar espaço para que as vozes, práticas e ações desses grupos sociais sejam visibilizadas. É nessa perspectiva que se enquadra o presente artigo ao buscar evidenciar ações e práticas locais de reivindicação social diante do avanço dos grandes projetos de mineração em Moatize. A ideia é valorizar o lugar e as práticas de resistência desses lugares enquanto formas alternativas de pensar criticamente sobre os projetos desenvolvimentistas impostos no terceiro mundo (Escobar 2005a; 2005b).

Diversas pesquisas socioantropológicas no Brasil têm denunciado o caráter socio ambientalmente violento e destruidor do neoex- 
trativismo (Marin 2010; Sant'Ana Júnior \& Alves 2018; Zhouri et al 2016, Castro et al 2016). A apropriação de terras cultivadas e aráveis devido à expropriação; à destruição dos recursos florestais; à poluição de recursos hídricos; ignorância e o desconhecimento dos direitos territoriais e étnicos; pressões e intimidações para o recebimento de indenizações mínimas e individuais, bem como a criminalização das ações de resistências caracterizaram a atuação e as práticas da empresas mineradoras no Brasil (Marin 2010).

As pesquisas têm mostrado também que as práticas socio ambientalmente agressivas das empresas mineradoras e de outros empreendimentos econômicos atingem em maior dimensão as populações de baixa renda (Acselrad 2004a; 2018). Alguns desses danos são conhecidos pelas empresas que pouco fazem para preveni-los (Zhouri et al 2016; Acselrad 2018; Marshall 2017). A articulação e cooptação dos atores políticos tem permitido a flexibilização dos procedimentos ambientais e a expansão da fronteira de exploração para os territórios protegidos. As empresas têm atuado para frear a titulação de territórios tradicionais (terras indígenas, reservas extrativistas e de desenvolvimento sustentável, terras quilombolas) ou redimensionar os seus limites deixando de fora as áreas de seus interesses, tal como vem acontecendo atualmente na Serra da Gandarela em Minas Gerais (Malerba 2014; Carneiro 2016). Ou seja, os lucros das empresas mineradoras se dão às custas da expropriação social e ambiental dos grupos étnicos e populações de baixa renda (Acselrad 2004b; 2018).

A atuação da Vale em Moçambique não foge a essa lógica. A chegada da multinacional brasileira transformou Moatize num campo de violação de direitos e, consequentemente, num campo de resistência. Numa autêntica afirmação local da cidadania, as populações atingidas desenvolvem ações locais de mobilização e reivindicação social contra as práticas violentas das empresas e, de modo geral, contra as 'contradições desastrosas' (Miglievich-Ribeiro 2014) da atual lógica desenvolvimentista que vem sendo implementada na região. De fato, o distrito de Moatize é hoje lugar de contestação de projetos globais 
inerentes à expansão do capital internacional, que se interceptam de forma violenta com histórias e modos de vida das populações locais (Mignolo 2003).

As ações coletivas de contestação que são desenvolvidas lá apresentam narrativas outras que denunciam o caráter violento, autoritário e colonial das empresas mineradoras. A realidade atual de vida das populações de Cateme nos ensina que o discurso de desenvolvimento e melhoria de vida e 'emprego para os vossos filhos' adotado pelos gestores das empresas multinacionais e atores governamentais não passa de um discurso de cooptação para o controle e exploração capitalista do seu território. Neste contexto, as populações compulsoriamente deslocadas, enquanto lamentam pela realidade atual de vida imposta perversamente pela empresa, enquanto resistem e se mobilizam coletivamente em defesa dos seus direitos, também se engajam em novos campos de possibilidade de sobrevivência cotidiana, seja como motoqueiro, seja com uma feirinha no mercado ou nas vias mais movimentadas da comunidade.

De uma coisa as populações de Cateme têm certeza: não há muito que esperar da empresa, muito menos do tal discurso de desenvolvimento e melhoria de vida que vem acompanhando o avanço desses grandes empreendimentos na região. Só eles mesmos podem ser sujeitos das suas trajetórias e histórias de vida. Esses novos campos de possibilidade de reprodução social econômica (ser motoqueiro ou ter uma feirinha) se, por um lado, dão visibilidade da condição de vulnerabilidade e sofrimento social (Magalhães 2007; Zhouri et al 2016) em que se encontram nesses 'novos lugares', por outro evidenciam que mesmo expropriadas das suas terras de reprodução social, econômica e cultural, violentadas, enganadas pelas falsas promessas e abandonadas nas áreas de reassentamentos, essas populações se negam a ser cúmplices da aniquilação da sua própria existência.

Um dos pontos de grande significância é a interferência positiva que as ações de resistência das populações afetadas pela Vale em Moatize estão tendo na redefinição das práticas das empresas mineradoras 
e, de modo geral, na forma como os projetos desenvolvimentistas nacionais vêm sendo implementados na região. Uma dessas interferências se materializou na aprovação do regulamento sobre o processo de reassentamento em 2012 (Moçambique 2012), três anos depois da execução do reassentamento da Vale, e foi de certa forma resultado das irregularidades cometidas e da pressão exercida sobre o governo por essas comunidades compulsoriamente deslocadas e pelas diversas ONGs nacionais e internacionais. Uma análise profunda sobre essa lei é imprescindível para aferir os seus impactos, bem como uma análise comparativa entre as práticas da Vale e as práticas das empresas mineradoras que estão se expandido atualmente para a região.

\section{Notas:}

1 Para mais abordagens sobre as dinâmicas da exploração das reservas de carvão de Moatize desde o tempo colonial, ver: Andrade (2016); Meneses (2014) e Miguel (2009).

2 Bebida alcoólica local produzida com base em Mapira (Sorghum bicolor) ou Milho (Zea mays).

3 Para uma abordagem teórica e conceitual sobre mobilização social ou coletiva, ação coletiva e protestos sociais, sua complexidade e mecanismos gerais de sua configuração, ver: Daniel Cefaï (2009; 2017a; 2017b) e Mutzenberg (2015). Este último tem a particularidade de explorar as especificidades de ações coletivas e movimentos sociais na África. O importante a reter em termos teóricos e conceituais é que a mobilização social ou coletiva "emerge quando os membros de coletividade se sentindo atingidos, direta ou indiretamente, por um 'distúrbio' em que são confrontados, definem-no como uma situação problemática e resolvem passar a ação" (Cefaï 2017a:190). O protesto social é uma forma de ação coletiva e o momento de visibilidade de um movimento ou mobilização social (Mutzenberg 2015). As mobilizações e os protestos sociais são um processo de indagação e revolta, mas também "de se envolver em processos de ação conjunta e de julgamentos político e construir, na pluralidade e conflitualidade, um mundo comum" (Cefaï 2017b:141). Outro conceito importante a reter no âmbito desse debate é o de 'arena publica' enquanto 'campos de experiência coletiva'; para isso, ver: Daniel Cefaï (2002; 2017a; 2017b).

4 A AAAJC é atualmente uma das principais associações da província de Tete, que atua na defesa dos direitos das comunidades locais atingidas pelas atividades de mineração, bem como na resolução de conflitos.

5 Ver por exemplo: https://adecru.wordpress.com/2013/12/24/familias-atingidas-pela-vale-forcam-a-paralisacao-geral-da-mina-de-mocambique/. Acesso no dia 
05/01/2020. Ver: https://atingidospelavale.wordpress.com/2015/05/25/as-consequencias-da-vale-em-moatize-mocambique/\#more-1158. Acesso no dia 05/01/2020.

6 A categoria 'aqui' é usada para diferenciar o novo lugar do antigo lugar, que normalmente é denominado de 'lá'. Não é exclusivamente espacial, em determinadas situações assume uma dimensão temporal com o sinônimo de 'hoje'.

\section{Referências:}

ACSELRAD, Henri. 2018. "Mariana, novembro de 2015: a genealogia política de um desastre". In ZHOURI, A. (eds.): Mineração, violências e resistências: um campo aberto à produção de conhecimento no Brasil, pp. 155-174. Marabá: Editorial iGuana/ ABA.

. 2004a. "De 'bota fora' e zonas de sacrifício - um panorama dos conflitos ambientais no Estado do Rio de Janeiro". In ACSELRAD, H. (eds.): Conflito social e meio ambiente no Estado do Rio de Janeiro, pp. 07-18. Rio de Janeiro: Relume Dumará/ Fase.

. 2004b. "Justiça ambiental - ação coletiva e estratégias argumentativas". In ACSELRAD, H., HERCULAN̉O, S. \& PÁDUA, J. A. (eds.): Justiça ambiental e cidadania, pp. 23-40. Rio de Janeiro: Relume Dumaná/ Fundação Ford.

AMARAL, Marina. 2016. "A multinacional que veio do Brasil. Vale conclui megaprojeto para exportação de carvão em Moçambique que expulsou mais de 10 mil pessoas e hoje emprega menos de 2 mil trabalhadores locais". Brasil: Agência Pública. (https://apublica.org/2016/02/a-multinacional-queveio-do-brasil/; acesso em 07/01/2020).

ANDRADE, Inácio D. 2016. Tem um espírito que vive dentro dessa pele: feitiçaria e desenvolvimento em Tete, Moçambique. Tese de Doutorado. São Paulo: UNICAMP.

BOURDIEU, Pierre. 2004. "A delegação e fetichismo político". In BOURDIEU, P. (Ed.): Coisas ditas, pp. 188-206. São Paulo: Brasiliense.

CARNEIRO, Eder Jurandir. 2016. "Atividades minerarias e conflitos ambientais e territoriais em Minas gerais, Brasil: trajetória histórica”. In ZHOURI, A., BOLADOS, P. \& CASTRO, E. (eds.): Mineração na América do Sul: neoextrativismo e lutas territoriais, pp. 255-278. São Paulo: Annablume.

CASTRO, E., ALONSO, S. \& NASCIMENTO, S. 2016. "Mineração na panamazônia: neoextrativismo, colonialidade e lutas territoriais". In ZHOURI, A., BOLADOS, P. \& CASTRO, E. (eds.): Mineração na América do Sul: neoextrativismo e lutas territoriais, pp. 155-180. São Paulo: Annablume.

CEFAÏ, Daniel. 2009. "Como nos mobilizamos? A contribuição de uma abordagem pragmatista para a sociologia da ação coletiva”. Dilemas: Revista de Estudos de Conflito e Controle Social, 2(4): 11-48.

. 2017a. "Públicos, problemas públicos, arenas públicas... O que nos ensina o pragmatismo (Parte 1)”. Novos estudos CEBRAP, 36(01):187-213. 
CEFAÏ, Daniel. 2017b. "Públicos, problemas públicos, arenas públicas... O que nos ensina o pragmatismo (Parte 2)". Novos estudos CEBRAP, 36(02):129-142. 2002. Qu'est-ce qu'une arène publique? Quelques pistes pour une approche pragmatiste. In CEFAÏ, D. \& JOSEPH, I. (eds.): L'heritage du pragmatisme. Conflits d'urbanité et épreuves de civisme, pp. 51-81. La Tour d'Aigues: Éditions de l'Aube. (http://lemetro.ifcs.ufrj.br/Cefai_arena_ publica.pdf; acesso em 05/10/2018).

ESCOBAR, Arturo. 2005a. "Imagining a post-development era?" In EDELMAN, M. \& HAUGERUD, A. (eds.): The anthropology of development and globalization: from classical political economy to contemporary neoliberalism, pp. 341-351. Malden: Blackwell Publishing.

" "O lugar da natureza e a natureza do lugar: globalização ou pósdesenvolvimento?". In LANDER, E. (ed.): A colonialidade do saber: eurocentrismo e ciências sociais. Perspectivas latino-americanas, pp. 133-168. Buenos Aires: Colección Sur-Sur, CLACSO.

GOVERNO DO DISTRITO DE MOATIZE. 2015. Dados sobre $1^{\circ}$ ponto de agenda da II sessão extraordinária do Governo Provincial de Tete: ponto da situação do processo de reassentamento. Moatize: Governo do Distrito de Moatize.

HUMAN RIGHTS WATCH [HRW]. 2013. "O que é uma casa sem comida?" O boom da mineração em Moçambique e o reassentamento". USA: HRW, 2013. (www.hrw.org/sites/default/files/reports/mozambique0513port_ ForUpload_0.pdf; acesso em 04/07/2014).

MAGALHÃES, Sônia B. 2017. Lamento e Dor. Uma análise sócio-antropológica do deslocamento compulsório provocado pela construção de barragens. Tese de Doutorado. Belém: Universidade Federal do Pará em co-tutela com a École Doctorale Vivant et Sócietés da Universidade Paris 13.

MALERBA, Julianna. 2014. "Apresentação: áreas livres de mineração: por que e para quê?" In MALERBA, J. (ed.): Diferentes formas de dizer não: experiencias internacionais de resistência, restrição e proibição ao extrativismo mineral, pp. 09-18. Rio de Janeiro: Fase.

MARIN, Rosa A. 2010. "Estratégias dos Quilombolas de Jamboaçu e projeto da Vale S.A. no Moju, Pará". In ALMEIDA, A. (ed.): Cadernos de debates nova cartografia social: territórios quilombolas e conflitos, pp. 49-61. Manaus: Projeto Nova Cartografia Social da Amazônia/ UEA Edições.

MARSHALL, Judith. 2017. "Rompimentos de barragens de rejeitos no Brasil e no Canadá: uma análise do comportamento corporativo”. Caderno Eletrônico de Ciências Sociais, 5(1):27-46.

MENESES, Isaú. 2014. Globalização, urbanização e culturas locais. Matola: Instituto Superior de Artes e Cultura (ISArC).

MERCANDALLI, Sara. 2015. "L'agriculture dans le sud du Mozambique, une activité fondeé sur les migrations de travail”. In BOSC, P. et al (eds.): Diversité des agricultures familiales: exister, se transformer, devenir, pp. 127-142. Paris: Éditions Quae. 
MERCANDALLI, S. \& ANSEEUW, W. 2014. "Migrations et stratégies des familles mozambicaines: réflexions pour une politique intégrée de développement rural”. Revue Tiers Monde, 4(220):61-79.

MIGLIEVICH-RIBEIRO, Adélia. 2014. "Por uma razão decolonial: desafios éticopolítico-epistemológicos à cosmovisão moderna”. Civitas, 14(1):66-80.

MIGNOLO, Walter. 2003. Histórias locais/projetos globais: colonialidade, saberes subalternos e pensamento liminar. Belo Horizonte: UFMG.

MIGUEL, Inês S. 2009. A Companhia Carbonifera de Moçambique: Evolução sócio-histórica no período 1950 - 1973. Dissertação de Mestrado. Porto: Universidade do Porto.

MIMBIRE, Fátima. 2016. Num contexto de crise das commodities: Desafios de um país potencialmente rico em recursos minerais. Estabelecendo as bases para evitar a 'maldição dos recursos' em Moçambique no novo 'super-ciclo' dos preços das matériasprimas. Maputo: Centro de Integridade Pública (CIP).

MOÇAMBIQUE. 2002. Lei no 14/2002 de 24 de junho: lei de Minas. Maputo: Boletim da República de Moçambique. . 2012. Lei no 31/2012 de 8 de agosto: regulamento sobre o Processo de Reassentamento Resultante de Atividades Econômicas. Maputo: Boletim da República de Moçambique.

MUTZENBERG, Remo. 2015. "Conhecimento sobre ação coletiva e movimentos sociais: pontos para uma análise dos protestos sociais em África". Sociedade e Estado, 30(02):415-447.

NOGUEIRA, Bruna. 2017. Vale inaugura Corredor Logístico de Nacala. Revista Mineração e Sustentabilidade. (http://revistamineracao.com. $\mathrm{br} / 2017 / 05 / 19 /$ vale-inaugura-corredor-logistico-de-nacala/; acesso em 03/10/2018).

OSÓRIO, C. \& CRUZ E SILVA, T. 2017. Corporações económicas e expropriação: raparigas, mulheres e comunidades reassentadas no distrito de Moatize. Maputo: WILSA.

PALHETA DA SILVA, João M. 2013. Território e mineração em Carajás. Belém: GAPTA/UFPA.

ROSSI, Amanda. 2015. Moçambique, o Brasil é aqui. Uma investigação sobre os negócios brasileiros na África. Rio de Janeiro: Record.

SANT'ANA JÚNIOR, H. \& ALVES, E. 2018. "Mina-ferrovia-porto: no 'fim de linha', uma cidade em questão". In ZHOURI, A. (ed.): Mineração, violências e resistências: um campo aberto à produção de conhecimento no Brasil, pp. 259-297. Marabá: Editorial iGuana/ ABA.

SANT'ANA JÚNIOR, H. \& CARDOSO, R. 2016. "O sistema mina-ferroviaporto e lutas territoriais no Maranhão". In ZHOURI, A., BOLADOS, P. \& CASTRO, E. (eds.): Mineração na América do Sul: Neoextrativismo e lutas territoriais, pp. 181-202. São Paulo: Annablume.

SITOE, C. \& QUEFACE, T. 2015. A minha voz: narração de sofrimento de comunidades reassentadas em Tete. Maputo: Sekelekani. 
VALE. 2017. Produção da Vale no 4T16. Brasil: Departamento de Relações com Investidores. (http://www.vale.com/PT/investors/information-market/ quarterly results/ResultadosTrimestrais/2016\%204Q\%20Production\%20 Report_p.pdf; acesso em 30/11/2018).

VELHO, Gilberto. 2013. Projeto e metamorfose, antropologia das sociedades complexas. Rio de Janeiro: Zahar.

WOORTMANN, Klaas. 2009. "Migração, família e campesinato". In WELCH, C. et al (eds.): Camponeses brasileiros: leituras e interpretações clássicas, pp. 217-238. São Paulo/Brasília: UNESP/NEAD.

ZHOURI, A. et al. 2016. "O desastre de Mariana: colonialidade e sofrimento social”. In ZHOURI, A., BOLADOS, P. \& CASTRO, E. (eds.): Mineração na América do Sul: Neoextrativismo e lutas territoriais, pp. 45-66. São Paulo: Annablume.

\begin{abstract}
Multinational Vale has established a megaproject for coal mining in the Moatize Carbon Bay, Zambezi Valley, in Mozambique's Central Region. Ever since, it has turned Moatize District into a field of forced displacement, violence and social conflict. This paper seeks to analyse different forms of resistance developed by forcibly displaced populations, their repertoires, demands and social implications. It advocates that these mostly rural populations (peasants, potters) claiming collective actions not only denounce violent, authoritarian and colonial practices by mining companies. They show other narratives towards a critical thinking on the current development logic in Mozambique, based on commodities exploitation and exports increase, and also have the potential to interfere positively in that region's developmental expansion.
\end{abstract}

Keywords: Mining, Megaprojects, Forced Displacements, Collective Actions, Resistance, Moatize.

Recebido em abril de 2020.

Aprovado em julho de 2020. 